\title{
Effectiveness of neuromuscular electrical stimulation in the functional knee rehabilitation in soldiers
}

\author{
Castillo-Lozano R. ${ }^{1}$
}

Sanid. mil. 2015; 71 (4): 239-246; ISSN: 1887-8571

\begin{abstract}
SUMMARY
Background: The versatility of military physical therapist practice enables them not only to diagnose knee injuries but also to provide a wide range of definitive care and rehabilitation, reducing the need for costly evacuation. The aim this study was to evaluate the effectiveness of interventions by Neuromuscular Electrical Stimulation (NMES) in the functional knee rehabilitation in soldiers and describe the main predictors and determinants in each intervention. Methods: A systematic search of the literature about NMES in physiotherapy was performed using the following electronic databases: Web of Science, PubMed, Cochrane, Physiotherapy Evidence Database (PEDro) and CINAHL. The search strategy was: "neuromuscular electrical stimulation" and "physical therapy" and "strengthening" and "knee". Inclusion criteria were: original articles published and peer reviewed between 2004-2015, focusing on physiotherapy interventions by NMES on subjects older than 18 years. A total resulting from 46 studies was included in the study. Results: The results show the evidence on the effectiveness of NMES therapeutic/preventive purposes in the muscular system; and the importance of physical therapy in the army. Conclusion: As a method of functional knee rehabilitation, NMES proves effective in achieving the therapeutic/preventive objectives in soldiers. Level of Evidence: II. Systematic review of randomized clinical trials with homogeneity.
\end{abstract}

KEYWORDS: Physical Therapy, Neuromuscular Electrical Stimulation, Strengthening, Knee.

\section{Eficacia de la estimulación eléctrica neuromuscular en la rehabilitación funcional de rodilla en soldados}

RESUMEN: Antecedentes: La versatilidad de la práctica de la fisioterapia militar nos permite no sólo el diagnóstico de lesiones de rodilla sino también para proporcionar una amplia gama de atención específica y rehabilitación, reduciendo la necesidad de una evacuación costosa. El objetivo de este estudio fue comparar la eficacia de las intervenciones de estimulación eléctrica neuromuscular (NMES) en la rehabilitación de rodilla funcional en soldados y describir los principales predictores y determinantes en cada intervención. Métodos: Se realizó una búsqueda sistemática de la literatura sobre la NMES en fisioterapia utilizando las siguientes bases de datos electrónicas: Web of Science, PubMed, Cochrane, Fisioterapia Evidence Database (PEDro) y CINAHL. La estrategia de búsqueda fue: "neuromuscular electrical stimulation" and "physical therapy" and "strengthening" and "knee". Se seleccionaron artículos originales publicados y revisados por pares entre 2004-2015, centrándonos en las intervenciones de fisioterapia mediante NMES en sujetos mayores de 18 años. Un total resultante de 46 estudios se incluyeron en el estudio. Resultados: Los resultados muestran la evidencia sobre la eficacia de los propósitos terapéuticos y preventivos de la NMES en rodilla; y la importancia de la fisioterapia en el ejército. Conclusión: La fisioterapia mediante su método NMES de rehabilitación de la rodilla resulta eficaz en el logro de los objetivos terapéuticos / preventivas en los soldados. Nivel de Evidencia: II. Revisión sistemática de ensayos clínicos aleatorizados, con homogeneidad.

PALABRAS CLAVE: Fisioterapia, estimulación eléctrica neuromuscular, Fortalecimiento, rodilla.

\section{INTRODUCTION}

Military physical therapists have established a long and respected tradition of setting the highest clinical practice standards in caring for military beneficiaries (active duty, dependents of active duty, retired, and dependents of retired), the example of which has been used to help develop the physical therapy profession as a whole. Practice standards continue to advance through emerging evidence, newer technology, more informed practice, and evidence-based guidelines ${ }^{1}$.

${ }^{1}$ Lecturer. University of Osuna. Physiotherapy Department. Sevilla. Spain.

Address correspondence: romu_castillo@hotmail.com//romualdocl@euosuna.org

Recibido: 28 de junio de 2015

Aceptado: 15 de julio de 2015
The impact of physical therapists on improving the health and military readiness of service members has garnered the support of the military's medical leadership to such a degree that they are regularly credentialed by local military hospitals and health care facilities with clinical privileges to: safely examine patients with and without physician referral; order diagnostic imaging; order laboratory tests; refer patients to other practitioners; initiate duty limitations; and perform electromyographic and nerve conduction studies ${ }^{1-6}$. Military physical therapists are often the first credentialed health care provider in the process of care to diagnose and treat patients with musculoskeletal injuries. Direct access to military physical therapists for treatment of patients with musculoskeletal conditions has proven to be effective, with minimal risk ${ }^{3,4,7}$.

Obviously, combat is not an athletic pursuit; however, the construct of treating service members as athletes provides many strategic advantages. Specifically, treating service members as tactical athletes provides a value model for preventing and treating musculoske- 


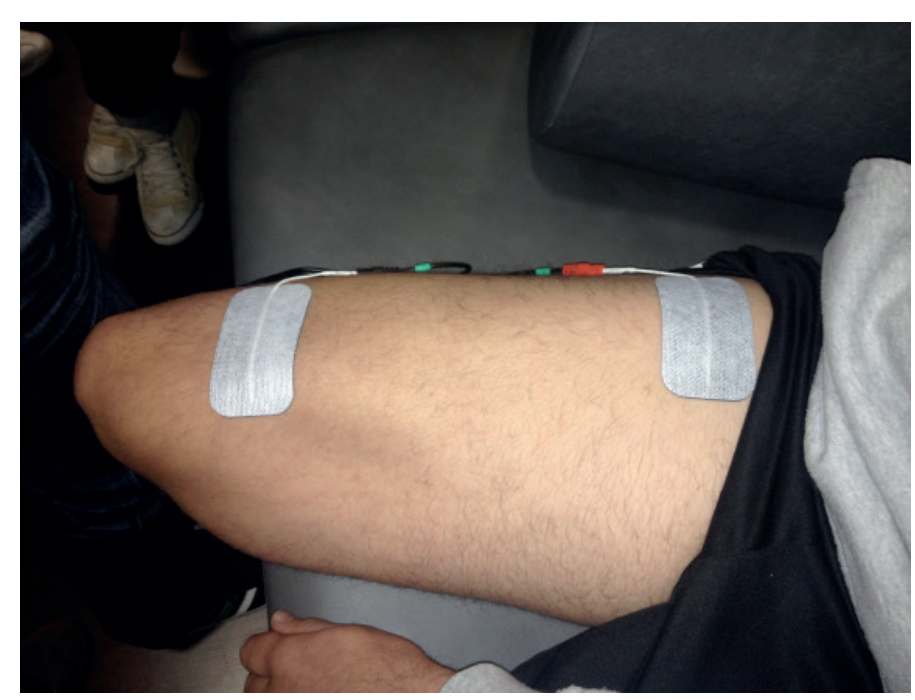

Figure 1. Electric strengthening through a symmetrical biphasic waveform.

letal injuries closer to the point and time of injury ${ }^{7}$. It now adds a rehabilitation capability to the combat zone whereby military physical therapists fully incorporate their vast competencies and capacity to treat patients under the most austere and dangerous environments. Physical therapist practice under these conditions not only entails all facets of evidence based practice in injury prevention and human performance optimization but also prompt and accurate diagnosis and intervention for musculoskeletal injuries. Treating service members closer to the point and time of injury, particularly in combat, is intended to maximize recovery and minimize secondary or chronic morbidity ${ }^{1,7}$. This musculoskeletal injury management practice is not new to physical therapists. In general, early access to physical therapy has been demonstrated to result in higher quality of care, reduced costs, improved patient satisfaction, enhanced recovery time, decreased work absenteeism, and prevention of chronic complaints ${ }^{7,8}$. Additionally, $80 \%$ of all musculoskeletal injuries were overuse injuries, with lower extremity overuse injuries listed as the number one cause of lost and limited days. The musculoskeletal injury rates are not unique to stateside assignments and occur in higher frequency in combat environments ${ }^{8}$. In a deployed setting (combat zone), nonbattle musculoskeletal injuries account for $87 \%$ of all injuries[6]. The rate of musculoskeletal injuries in deployed settings is estimated to occur 6.5 to 7 times more frequently than combat-related injuries ${ }^{6}$.

As we can see, most injuries in soldiers occur in the knee. Neuromuscular Electrical Stimulation (NMES) is a modality in the field of Clinical Physiotherapy used for exercise and/or rehabilitation. NMES is defined as the application of an electric current using surface electrodes mounted on skeletal muscles to produce a visible muscle contraction through activating intramuscular nerve branches and thus restore normalcy or stabilize the treatment area ${ }^{9}$. Many studies have shown the benefits of combining NMES programmes with active knee exercises to improve muscle strength and prevent joint diseases ${ }^{10-14}$. Among the therapeutic modalities, NMES is presented as a noninvasive technique used by physiotherapists to promote muscle strengthening ${ }^{11-13,15}$, to minimize muscular hypotonia ${ }^{12,16}$, to reduce muscle spasm $^{14}$ and restore function ${ }^{12,13,15,16}$. The musculoskeletal system is largely somatic musculature of the body, led by nerve stimulation and under the control of the will ${ }^{17}$. Within this system, tonic motor units ( $\alpha 2$ tetanus frequency $20-30 \mathrm{~Hz}$ ) are the first to be activated by movement and phasic motor units ( $\alpha 1$ tetanus frequency of $50-150 \mathrm{~Hz}$ ) are activated when motion requires an extra effort; in the case of a rapid phasic movement this can become activated before tonic motor ${ }^{17,18}$. The main functions of this system are: output power for locomotion and respiration; force production support for the position; and heating during cold exposure ${ }^{19}$. So by NMES we can influence these aspects vital to achieving full autonomy and proper functioning of our body.

The purpose of this systematic review was to evaluate the effectiveness of interventions through NMES on the functional knee rehabilitation in soldiers and describe the main predictors and determinants in each intervention.

\section{MATERIAL AND METHODS}

\section{Search strategy}

For the investigative process we first concentrated on studies focussing on strength gains in quadriceps muscle. A systematic search of the literature on NMES in physiotherapy was performed using the following electronic databases: Web of Science, PubMed, Cochrane, Physiotherapy Evidence Database (PEDro) and CINAHL. The search strategy was: "neuromuscular electrical stimulation" and "physical therapy" and "strengthening" and "knee". Inclusion criteria were: original articles published and peer reviewed between 2004-2015, focusing on physiotherapy interventions in knee by NMES in subjects older than 18 years; only articles written in English and minimum study duration of $\geq 7$ days, comparable tests such as pretests, posttests and retests. Only studies with homogeneous groups on a comparable level of fitness were considered in this review. Significant gains for the training group were documented in relation to the baseline and the difference to the control group in posttesting.

About $60 \%$ of them were found with the help of scientific search engines such as Web of Science, PubMed, Cochrane, Physiotherapy Evidence Database (PEDro) and CINAHL and directly

Table 1. Descriptive Data Comparing Physical Therapy Workload With All Outpatient Workload From Combat Support Hospitals During Operation Iraqi Freedom From July 2004 to December 2010 (Moore et al., 2013) ${ }^{6}$.

\begin{tabular}{|lcc|}
\hline \multicolumn{1}{|c}{ Description of Workload } & $\begin{array}{c}\text { Workload } \\
\text { Data }\end{array}$ & $\%$ \\
\hline $\begin{array}{l}\text { Physical Therapy workload/combat Support } \\
\text { Hospitals Total outpatient workload }\end{array}$ & $38410 / 84790$ & $45.3 \%$ \\
$\begin{array}{l}\text { Musculoskeletal injuries managed by physical } \\
\text { therapists compared with all other providers }\end{array}$ & $34009 / 37332$ & $91.1 \%$ \\
$\begin{array}{l}\text { Physical Therapy new evaluations / physical } \\
\text { therapy outpatient workload }\end{array}$ & $22431 / 38410$ & $58.4 \%$ \\
$\begin{array}{l}\text { Physical Therapy new evaluations seen through } \\
\text { direct acess }\end{array}$ & $10116 / 22431$ & $44.9 \%$ \\
$\begin{array}{l}\text { Soldiers returned to work, treated by physical } \\
\text { therapists }\end{array}$ & $21602 / 22431$ & $96.1 \%$ \\
\hline
\end{tabular}




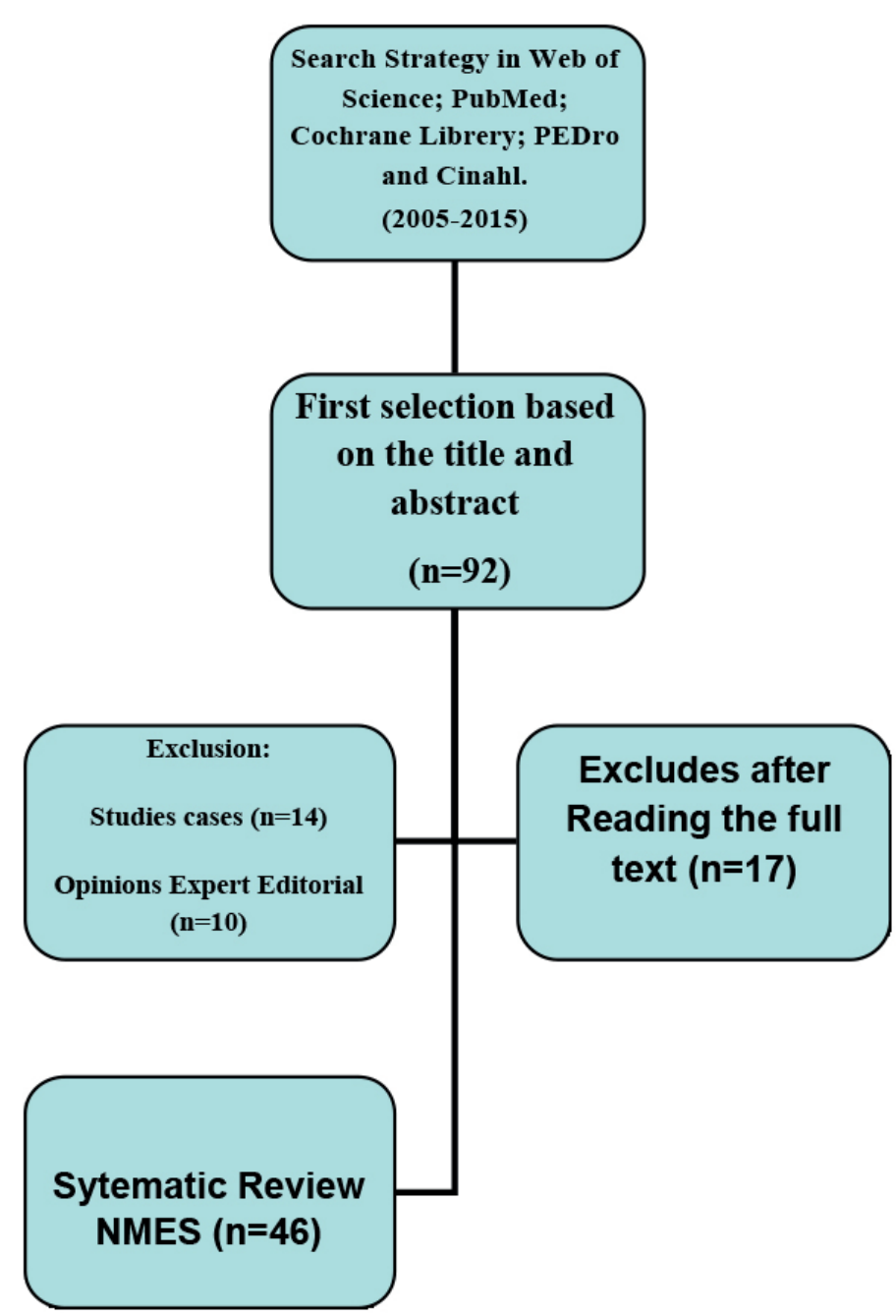

Figure 2. Flowchart of the review procedure.

on journal data bases such as JSCR. The other $40 \%$ were found through references within these studies. First, we rely on the title and abstracts of the resulting articles, where we obtained an initial selection of 92 studies. Then all items were read critically. The items that did not meet the inclusion criteria were removed. In addition, all studies, expert opinions and systematic reviews were excluded. As a final step, studies that formed the reference lists of all systematic reviews, and who met the inclusion criteria, were searched and analysed. The most questionable items were discussed with a second and third evaluator experts in the field. A total of 46 studies were included in this study (Figure 2).

\section{Data classification}

The review began by selecting a total of 46 studies. From this pool of investigations, all trials in which male and female subjects formed different training groups or in which more than one NMES group (with different NMES method) was trained or tested with different parameters were once again divided into individual trails. For example, studies investigated two types of NMES methods, the trials were split and each was sorted to a specific sub group (e.g. isometric NMES, combination NMES etc.).
Table 2. Musculoskeletal Injury by Body Part Managed by Brigade Combat Team Physical Therapists (Moore et al., 2013) ${ }^{6}$.

\begin{tabular}{|lcc|}
\hline Location of Injury & Patients $(\mathbf{n})$ & $\mathbf{\%}$ \\
\hline Knee & 25.332 & 21.3 \\
Lumbar Spine & 24.618 & 20.7 \\
Leg/ankle/foot & 22.358 & 18.8 \\
Cervical Spine & 14.747 & 12.4 \\
Shoulder & 12.131 & 10.2 \\
Tharacic Spine & 8.206 & 6.9 \\
Hip/Pelvis & 6.184 & 5.2 \\
Elbow/wrist/hand & 5.351 & 4.5 \\
\hline Total & 118.927 & 100 \\
\hline
\end{tabular}

To represent this large number of studies and their results clearly, the trials were classified according to the type of NMES method (local NMES methods - stimulation of defined muscle groups with single electrodes; whole-body NMES methods - stimulation and activation of several muscle groups simultaneously through a electrode belt system, agonist and antagonist are activated at the same time) and type of muscle contraction (e.g. isometric NMES, dynamic NMES). The combination NMES method is a subgroup for both types of stimulation. In combination methods, the types described above are combined with additional specific training (e.g. conventional weight training, plyometric jump training).

\section{Classification and grading of different outcomes}

The classification and qualification outcomes: classification level of evidence (Table 3); conduct and score of each item was performed by three independent raters - 1 Doctor of Physical Therapy, 1 Therapist working in Research and 1 Therapist with a Master in Scientific Evidence in Health Sciences. The evaluators ranked the search results by: the structure and function of the body; activities and participation; personal factors and environmental factors.

\section{Level of evidence}

The same independent evaluators rated the studies according to their level of evidence. Level I evidence is the most definitive in establishing causality, with further reduction of bias. Evidence levels IV-V can only allude to causality. The unweighted Kappa coefficient varied from 0.732 to 0.937 .

In a second step, all discrepancies were discussed. The evaluators argued the reasons for the score given to reach a consensus. The final consensus was the score used in the summary tables. Within the categories, the assorted studies were put into tables. To compare the results and or point out relationships between certain parameters, extreme data was eliminated. To show the strength variances between pretesting, posttesting and retesting, all results have been converted into percentages. In references to significance levels or confidence intervals, an $\alpha$-level of 0.05 was used, which corresponds to a $95 \%$ confidence interval. For correlation comparisons the level of significance was established at $\mathrm{p}<0.05$. 


\section{R. Castillo-Lozano}

Table 3. Hierarchy of levels of evidence based on the types of research design (Moore et al., 2013) ${ }^{6}$.

\begin{tabular}{|c|c|c|}
\hline Level & Intervention of individual studies & Research design a single issue \\
\hline I & $\begin{array}{l}\text { - Review Systematic randomized controlled trials (RCTs). } \\
\text { - RCTs Great with narrow confidence intervals ( }>100) \text {. }\end{array}$ & $\begin{array}{l}\text { - Randomized Controlled trial (RCTs). } \\
\text { - Design of AC treatment. } \\
\text { - Design of concurrent or non-concurrent multiple baseline. } \\
\text { - These designs can provide causal interference. }\end{array}$ \\
\hline II & $\begin{array}{l}\text { - RCTs Ones with wider confidence intervals }(\mathrm{n}<100) \text {. } \\
\text { - The Systematic review of cohort studies. } \\
\text { - Results Research (major ecological studies). }\end{array}$ & $\begin{array}{l}\text { - Controlled-studies nonrandomized concurrent. } \\
\text { - Interferences Limited grounds. }\end{array}$ \\
\hline III & $\begin{array}{l}\text { - The Cohort studies with concurrent control group. } \\
\text { - The Systematic reviews of case-control studies. }\end{array}$ & $\begin{array}{l}\text { - Not randomized, non-concurrent. } \\
\text { - Interferences Limited grounds. }\end{array}$ \\
\hline IV & $\begin{array}{l}\text { - The Case series. } \\
\text { - The Cohort studies without concurrent control group. } \\
\text { - Case-control-studies. }\end{array}$ & $\begin{array}{l}\text { - Not randomized controlled at least three phases (ABA, ABAB, BAB, } \\
\text { etc.). } \\
\text { - It only refers to the causal interference. }\end{array}$ \\
\hline V & $\begin{array}{l}\text { - The Expert opinion. } \\
\text { - Case Study or report. } \\
\text { - A Experts on the basis of theory or physiological research. } \\
\text { - The Common-sense anecdotes. }\end{array}$ & $\begin{array}{l}\text { - Controlled Nonrandomized AB. } \\
\text { - Suggest causal interference that allow testing of ideas. }\end{array}$ \\
\hline
\end{tabular}

Table 4. Parameters commonly used for the treatment / prevention of knee injuries (2004-2015).

\begin{tabular}{|c|c|}
\hline \multicolumn{2}{|r|}{46 studies } \\
\hline Pulse type & $\begin{array}{l}\text { The most effective Interferential impulse is followed by biphasic pulse (more easily used by the acquisition); single phase; and } \\
\text { Russian current. }\end{array}$ \\
\hline Pulse shape & $\begin{array}{l}\text { The most effective way to NMES is sinusoidal, although } 48 \% \text { of the studies used a square or rectangular symmetrical (ease of } \\
\text { acquisition pulse shape), } 27 \% \text { of alternating sinusoidal pulse, and } 15 \% \text { with triangular pulses. }\end{array}$ \\
\hline Pulse Width & On average, a pulse width of $261 \pm 132 \mu$ s was used. A width of $200 \mathrm{mS}-400 \mu$ s was applied in $48 \%$ of study designs. \\
\hline Pulse frequency & $\begin{array}{l}\text { The frequency varied between } 25-2500 \mathrm{~Hz} \text {. When NMES is applied it is possible to produce a block of muscle activity (muscle } \\
\text { fatigue) due to failure propagation or depletion of neurotransmitters. So, we work in pursuit of fatigue and rapid recovery } \\
\text { (average frequency } 2500 \mathrm{~Hz} \text { ), or use a lower frequency to } 50 \mathrm{~Hz} \text { for lower muscle fatigue associated with a much } \\
\text { slower recovery (low frequency } 40 \mathrm{~Hz} \text { ). }\end{array}$ \\
\hline Intensity impulse & Must be the maximum tolerated (milliAmps). \\
\hline Time Impulse & $\begin{array}{l}\text { Varied between 3-60 seconds (time of contraction) and 4-180 seconds between pulses (Duty Cycle }=1: 3 \text {. Standard, but this } \\
\text { relationship can be modified to accommodate patient needs and the treatment's objectives). }\end{array}$ \\
\hline
\end{tabular}

Table 5. Descriptive Data Comparing Physical Therapy Workload With Total Workload for Physical Therapists Assigned to Brigade Combat Teams During Operation Iraqi Freedom/Operation Enduring Freedom From August 2005 to March 2011 (Moore et al., 2013$)^{6}$.

\begin{tabular}{|lc|}
\hline Description of Workload & Workload Data \\
\hline Physical Therapy workload/brigade total workload & $118.927 / 332.197$ \\
Physical Therapy new evaluations/physical therapy outpatient workload & $48.879 / 118.927$ \\
Physical Therapy new evaluations seen through direct access & $21.653 / 48.879$ \\
Soldiers returned to work treated by Physical Therapists & $47.852 / 48.879$ \\
\hline
\end{tabular}

\section{RESULTS}

The analysis of the selected studies showed that more than half of the trials tested male subjects. Studies with exclusive female subjects or a mixed sample had a stake of $20 \%$. All subjects were classified as healthy and unimpaired and had no history of injury in the tested muscle group. On average, 10.6 subjects were examined over an average of 5 weeks. However, the majority of the studies (68\%) contained a stimulation period of 4-6 weeks. The number of training sessions varied from 1-7 sessions per week. An average of 16.3 sessions was completed within the training period, with a duration of $17.6 \pm 10.7$ minutes per session.

\section{Parameters in NMES}

After a thorough analysis of the scientific literature over the past 10 years, the parameters used in NMES should be: 


\section{Role of Military Physical Therapists in Recent Combat Campaigns}

Now, we show quantitatively important of physiotherapy in the army from 2005 to 2011.

\section{DISCUSSION}

As a method of functional knee rehabilitation in soldiers, NMES represents a promising alternative to traditional exercises to systematically improve strength parameters and motor skills. Scientific evidence shows that subjects whose aim is to gain therapeutic or functional strength, combining NMES with controlled and directed exercise should work.

\section{Size of the electrodes, waveform and associated parameters for NMES}

Forrester \& Petrofsky examined the effect of the size and shape of the electrode, waveform and associated pain response during $\mathrm{NMES}^{18}$. This research showed that there was little difference between the size or shape of the electrode and the development of quadriceps strength in a NMES. This was surprising because, intuitively, a larger electrode should recruit more motor units in the muscle since NMES was dispersed over a larger muscle area ${ }^{19}$. However, it was shown that the sine wave modulated type was more effective than stimulation by a square or rectangular wave in obtaining muscle contraction with significant potential recruitment ${ }^{20}$.

Another factor to consider is the spacing of the electrodes in the NMES. Petrofsky et al. studied this stimulation with different frequencies, size of the electrodes, current amplitudes, and pulse widths. The results were that changes in the stimulation pulse width and frequency had little effect on the penetration depth of the current in the muscle but it induced pain. However, this does not mean that the wider pulse widths do not transfer more power to the motor nerves that innervate the muscles and therefore allow a strong muscle contraction ${ }^{21,22}$. The parameters that influence the penetration of the current were:

1. The spacing of the electrodes alter the penetration depth: When the electrodes had a $10 \mathrm{~cm}$ or less of difference regardless if the electrode was large or small, the current was significantly higher in the central line between electrodes ${ }^{23}$. Furthermore, the current penetration into the muscle was greater. Therefore, to stimulate a quadriceps muscle, the electrode placement must be specific and the distance between them must be small.

2. Stimulation by a sine wave has different current transfer characteristics compared to the rectangular wave stimulation: While on the skin, the change of sinusoidal or rectangular did not deliver any difference in currents; in muscle stimulation sine wave created between $25-50 \%$ more current than did stimulation by rectangular wave. This explanation may be related to the fat layer. The fat layer forms a dialectric strength because of its high electrical resistance; high capacitance is developed by the high conductivity of the skin and muscle driven by the separation of the fat ${ }^{24,25}$. Therefore, the sine wave passes through a condenser without altering the energy field, while a rectangular wave changes shape by passing through a filter capacitor and loses energy ${ }^{25,26}$, which would lead to an increase in the amplitude and cause pain ${ }^{18}$.

\section{Placement of electrodes: Comfortable quadriceps muscle contraction}

Regarding the placement of the electrodes, the evidence confirms the influence of the positioning of the electrodes and their relationship with the perception of discomfort and/or pain during stimulation NMES, and the relationship between the depth of stimulation sites and mechanical-metabolic response-induced quadriceps muscle ${ }^{27,28}$. The motor point stimulation on muscle causes increased muscle metabolic mechanical stress, which represents the basic factors for muscle strengthening and adaptation. It also means that the motor point stimulation causes the stimulus to be more bearable, avoiding rapid onset of fatigue induced by sustained tetanic stimulation ${ }^{27,29}$.

The size of the electrode, as we have discussed above, is not directly related to the degree of muscle contraction or the perceived pain. But qualifying the latter, it is very important that the choice of electrodes is suitable to the area to be stimulated and if we use very small electrodes to stimulate a large area, the amplitude has to be high and can cause painful stimulation before reaching a sufficient quadriceps muscle contraction to allow strength training ${ }^{30}$. Therefore the selection of appropriate electrode size is essential for comfortable stimulation, all with specific electrode placement on the muscle motor to reduce the required amplitude threshold point.

\section{Signal analysis: Placement of electrodes at Point Motor vs Placement according to the book for the equipment}

To analyse the signal, the contractile parameters were evaluated: peak contraction, tetanus tension and tension-time area, calculated as the area between the baseline and the voltage signal ${ }^{27,28}$. To study the metabolic disturbances induced by contractions elicited with both forms of stimulation, oxy-hemoglobin $\left(\mathrm{O}_{2} \mathrm{Hb}\right)$ was measured, the deoxy-hemoglobin (HHB), the tissue oxygenation index (TOI), and the total index normalized hemoglobin (THI) Referring to the baseline, the greater the corresponding negative change during contraction values were $\mathrm{O}_{2} \mathrm{Hb}$, TOI and THI; and corresponding to the largest positive change values during the recovery period were $\mathrm{HHB}$ and $\mathrm{THI}^{27}$. So it is shown that when the motor point is stimulated, mechanical and metabolic stress on the quadriceps muscle is greater ${ }^{27}$.

The method of stimulation is a key factor in determining the muscle induced functional improvements NMES. Unlike when following the instructions which come with the equipment, which is adopted by most professional and non-professional users, the mode motor point stimulation elicited significantly higher mechanical responses evaluated by the peak voltage during single twitches; maximum tetanic tension; and the area under the time-voltage curve ${ }^{27}$ In particular, the voltage-time area has proved to be adequate for estimating the actual work performed by the motor unit recruitment parameter and, therefore, to predict the effectiveness of quadriceps muscle contraction. The scientific evidence says that this area is pro- 
portional to the energy used for the contraction of skeletal muscle fibres during brief periods of isometric activity ${ }^{31}$. On this basis, optimal stimulation is obtained when a contraction (power) is reached during stimulation of the motor point of the quadriceps muscle ${ }^{1}$.

The motor point stimulation showed statistically significant changes in metabolic parameters when compared to the challenges suggested by a guide that comes with the NMES equipment ${ }^{32}$. The energy required to maintain ATP turnover during muscle contraction is initially derived from immediate intramuscular phosphocreatine subsequently restored in the recovery phase by oxidative metabo$\operatorname{lism}^{33}$. The higher oxygen consumption after muscle contraction, the greater the energy expenditure during the following quadriceps muscle contractions. At the point when the motor is energized, HHB increased during recovery, suggesting a higher metabolic stress ${ }^{27}$. Moreover, considering that the regulation of muscle perfusion depends proportionally on the local release of metabolites automatic adaptation hyperemic response was observed in the recovery pha$\mathrm{se}^{34}$. The decrease in tissue oxygen saturation during contraction has been attributed to improved cellular uptake by mitochondria oxygen as resulting from increased metabolism of the active motor units and intramuscular increased pressure reduces blood supply and oxygen in muscle fibres ${ }^{34}$.

\section{TENS stimulation protocol}

One of the most used in treatment by electrical equipment is the TENS strengthening. Its acquisition and effectiveness/cost make it an item widely used by physiotherapists ${ }^{35,36}$. After reviewing recent studies, we can see that TENS parameters vary between studies. Pulse frequencies ranged from 25 to $100 \mathrm{~Hz}$; phase duration ranged from 140-600 milliseconds (ms), pulsed wave varied between monophasic and biphasic symmetrical. Similarly, therapy times ranged from 15-60 minutes per day, 3-5 days a week, and between 4-12 weeks of treatment. Despite this variation in parameters, using symmetrical biphasic current pulses, preferably using as benchmarks between $250-400 \mathrm{~ms}$ duration of phase with stimulation frequencies between $40-80 \mathrm{~Hz}$ and the highest intensity tolerated by the subject, all suggested it as the ideal intervention for quadriceps muscle strengthening ${ }^{37}$, as the muscle work is assimilated to that made with regular exercises to improve strength levels.

\section{Immune response during and after the electrical capacity by NMES}

The proper functioning of the immune system is essential for good health. In recent years, great effort has been invested in clarifying the possible health risks from electromagnetic fields of the environment and the different artificial sources ${ }^{38}$. NMES is used as a complementary tool for muscle strengthening, either in clinical practice or for preventive purposes. The stimulation parameters to test the influence of NMES in the immunology system were measured by monophasic rectangular pulses of $0.3 \mathrm{~ms}$ width and frequency of $20 \mathrm{~Hz}^{39}$. The intensity of electrical stimulation remained below the pain threshold (tolerable limit - not tolerable). This was enough to cause a contraction of the muscles stimulated. Electrical stimulation was cyclic (7seg / 7seg), lasting 20 minutes.
There was no statistically significant change or clinically significant effect on the immunological changes after application of NMES ${ }^{40}$ :

- Biochemical Determination of sodium, potassium, calcium, chloride, glucose, urea, creatinine, creatine kinase, cortisol and C-reactive protein (CRP).

- Differential white blood cells (leukocytes, lymphocytes, neutrophils, monocytes).

- Determination of the lymphocytes with the following characteristics: CD3, CD19, CD4, CD8, CD4 / CD8, HLA-DR / $\mathrm{CD} 3, \mathrm{CD} 56+\mathrm{CD} 4+\mathrm{CD} 25+(\mathrm{Th}$ reg $), \mathrm{CD} 25+\mathrm{CD} 3+, \mathrm{CD} 4$ $+\mathrm{CD} 25+, \mathrm{CD} 25+\mathrm{CD} 8+, \mathrm{CD} 69+\mathrm{CD} 3+, \mathrm{CD} 4+\mathrm{CD} 69+$, $\mathrm{CD} 8+\mathrm{CD} 69+$.

- Test phagocytosis of FITC-labelled neutrophil granulocytes E. coli (FTG), proof of phagocytosis of monocytes with FITC labeled E. coli (FTM).

- Test E. coli oxidative cleavage of neutrophilic granulocytes stimulated with dihydrorhodamine 123 (ECG).

- Test oxidative cleavage of E. coli stimulates monocytes with dihydrorhodamine 123 (ECM).

Electrical stimulation resulted in the acceleration of immune processes (IgM, IgG, IgA, T and B lymphocytes) activity and regenerative processes. As NMES can be used in healthy people for preventive purposes, and people affected by muscle disease for therapeutic purposes ${ }^{41}$, this leads to the certain conclusion that treatment with NMES does not produce significant physiological changes in the immune system.

\section{Influence of gender on NMES}

NMES should be similar to the response of the subject's voluntary contractions $\mathrm{s}^{42,43}$. NMES response can be determined by the intrinsic properties of the individual tissue ${ }^{18,24-26,41,44,45}$. Because men tend to have a higher proportion of muscle mass and a lower proportion of fat tissue they may be more sensitive to $\mathrm{NMES}^{46}$. Some studies with healthy individuals have examined gender differences in terms of strength induced by NMES and tolerance to the intensity of the current, where it has been shown that male subjects tolerate stronger contractions with electrical NMES than women ${ }^{46}$. However, when the strength of the electrical contraction was expressed in terms of a percentage of maximum voluntary isometric contraction and strength gain, no gender differences were demonstrated. All force measurements increased significantly over time in men and women, and the pattern of habituation to the current intensity was similar for both genders ${ }^{41,44,46}$.

\section{There is a need to put Army physical therapists in either combat zone?}

The answer would be no if strictly utilized as a prescription service with the use of historical definitions of long-term rehabilitation. However, using the sports medicine model, US Army physical therapists were deemed to be a valuable asset to not only the medical team but equally to the warfighters because of their ability to prevent, 


\section{Effectiveness of neuromuscular electrical stimulation in the functional knee rehabilitation in soldiers}

diagnose, and manage musculoskeletal injuries while providing an opportunity for the orthopedic surgeons to focus on the multi-trauma surgical cases associated with a war zone.

\section{What Does It All Mean?}

Military physical therapists do not practice independently but work interdependently with orthopaedic surgeons, family medicine and emergency care physicians, and physician assistants to help ensure optimal outcomes for military service members and beneficiaries $^{5}$. By functioning in a primary care direct access role to manage orthopedic and musculoskeletal injuries, military physical therapists are able to work more efficiently and effectively, reducing excessive patient visits, initiating evidence-based rehabilitation closer to the location and time of injury, while ensuring that serious injuries are expedited to orthopedic surgeons ${ }^{5}$. This close working relationship between the physical therapists and all credentialed providers enables the physical therapists to autonomously manage musculoskeletal injuries, providing the orthopaedic surgeons, family medicine, and emergency department physicians the opportunity to treat patients with more complex surgical and medical problems. The management of musculoskeletal injuries over several decades by military physical therapists within their respective stateside hospitals enabled these providers an easy transition to administering the same high level of evidencebased care in Iraq and Afghanistan 1,7 "Sports medicine" is an eclectic term, with no medical profession having exclusive rights to the name. Military physical therapists have long practiced sports medicine in their primary care direct access role for managing musculoskeletal injuries, both in stateside hospitals and now combat ${ }^{1-4}$. We suggest most physical therapists serving their patient population in the management of musculoskeletal injuries through primary care direct access are practicing sports medicine without calling it such. The premise that this level of practice is effective is anecdotally supported by the descriptive musculoskeletal injuries and direct access data reflecting the value added benefit of physical therapists to the team of physicians and other providers in the CSH, plus the physicians and physician assistants in BCTs and battalion aid stations ${ }^{7}$. We additionally propose that the efficacy for rehabilitation in an austere environment allows the tactical athlete to continue working in their deployed assignments while reducing the need to medically evacuate those with nonemergent findings. It is further supported when one looks at the high percentages of patients returned to duty?

\section{CONCLUSIONS}

The presence of physiotherapy as a discipline in the army is very important. However, the more important point is that whatever the method used in physical therapy, the cost of evacuating even a single service member is substantial, thus assessing opportunities to retain and rehabilitate service members in theater so that they can return to duty as quickly as possible should be a paramount health care priority.

As a method of functional knee rehabilitation, NMES proves effective in achieving the therapeutic/preventive objectives. Malpractice (not stimulating the motor point, distance and size of the erroneous electrodes,...) is the most common factor for poor perfor- mance in daily practice. After a thorough analysis of the scientific literature over the past 10 years, the parameters used in effective NMES are found to be: Interferential sinusoidal pulse $(2500 \mathrm{~Hz})$ or symmetrical biphasic $(40 \mathrm{~Hz})$; with a pulse width of $261 \pm 132 \mu \mathrm{s}$; the intensity should be the maximum tolerated; and stimulation time varied between 3-60 seconds and 4-180 seconds rest (Duty Cycle $=$ 1: 3 Standard).

Funding: The authors, their immediate families, and any research foundations with which they are affiliated have not received any financial payments or other benefits from any commercial entity related to the subject of this article.

Conflict of interest: The authors declare that they have no competing interests.

\section{REFERENCES}

1. Moore JH, Goss DL, Baxter RE, et al. Clinical diagnostic accuracy and magnetic resonance imaging of patients referred by physical therapists, orthopaedic surgeons and non-orthopaedic providers. J Orthop Sports Phys Ther. 2005;25:67-71.

2. Moore JH, McMillian DJ, Rosenthal MD, Weishaar MD. Risk determination for patients with direct access to physical therapy in military health care facilities. $J$ Orthop Sports Phys Ther. 2005;35:674- 678.

3. Childs JD, Whitman JM, Sizer PS, et al. A description of physical therapists knowledge in managing musculoskeletal conditions. BMC Musculoskel Disord. 2005;6: 32.

4. Childs JD, Whitman JM, Pugia ML, et al. Knowledge in managing musculoskeletal conditions and educational preparation of physical therapists in the uniformed services. Mil Med. 2007;172:4:440-445.

5. Moore JH, Goffar SL, Teyhen DS, Pendergrass TL, Childs JD, Ficke JR. The role of U.S. military physical therapists during recent combat campaigns. Phys Ther. 2013 Sep;93(9):1268-75. doi: 10.2522/ptj.20120136. Epub 2013 May 2.

6. Rosenthal MD, Moore JH, DeBerardino TM. Diagnosis of medial knee pain: atypical stress fracture about the knee joint. J Orthop Sports Phys Ther. 2006;36:526- 534

7. Ambulatory visits among members of the active component, U.S. Armed Forces, 2010. MSMR. 2010;18:16 -21.

8. Causes of medical evacuations from Operations Iraqi Freedom (OIF), New Dawn (OND), and Enduring Freedom (OEF), active and reserve components, U.S. Armed Forces, October 2001-September 2010. MSMR. 2011;18:2-7.

9. Maffiuletti NA. Physiological and methodological considerations for the use of neuromuscular electrical stimulation. Eur J Appl Physiol., 2010; 09;110(2):223-234.

10. Monaghan B, Caulfield B, O’Mathúna D,P. Surface neuromuscular electrical stimulation for quadriceps strengthening pre and post total knee replacement. The Cochrane database of systematic reviews, 2010. (1):1.

11. Tok F, Aydemir K, Peker F, Safaz I, Taşkaynatan MA, Ozgül A. The effects of electrical stimulation combined with continuous passive motion versus isometric exercise on symptoms, functional capacity, quality of life and balance in knee osteoarthritis: randomized clinical trial. Rheumatol Int., 2011; 02;31(2):177-181.

12. Vaz MA, Baroni BM, Geremia JM, Lanferdini F, Mayer A, Arampatzis A. Neuromuscular electrical stimulation (NMES) reduces structural and functional losses of quadriceps muscle and improves health status in patients with knee osteoarthritis. Journal of orthopaedic research: official publication of the Orthopaedic Research Society. 2013; 04;31(4):511-516.

13. Walls RJ, McHugh G, O'Gorman D,J., Moyna NM, O'Byrne J,M. Effects of preoperative neuromuscular electrical stimulation on quadriceps strength and functional recovery in total knee arthroplasty. A pilot study. BMC musculoskeletal disorders 2010;11:119.

14. Zeni JA, Snyder-Mackler L. Early postoperative measures predict 1- and 2-year outcomes after unilateral total knee arthroplasty: importance of contralateral limb strength. Phys Ther; 2010. 01;90(1):43-54.

15. Elboim-Gabyzon M, Rozen N, Laufer Y. Does neuromuscular electrical stimulation enhance the effectiveness of an exercise programme in subjects with knee osteoarthritis? A randomized controlled trial. Clin Rehabil., 2013; $03 ; 27(3): 246-257$. 


\section{R. Castillo-Lozano}

16. Bruce-Brand R, Walls RJ, Ong JC, Emerson BS, O'Byrne J,M., Moyna NM. Effects of home-based resistance training and neuromuscular electrical stimulation in knee osteoarthritis: a randomized controlled trial. BMC musculoskeletal disorders, 2012;13:118.

17. Dângelo JG, Fattini CA. Human Anatomy and systemic Segment. ed. Rio de Janeiro 2007: Atheneu.

18. Forrester B, Petrofsky JS. Effect of electrode size and shape on electrical stimulation. Eur J Appl Physiol., 2004; 4:346-354

19. Hoffman LR, Field-Fote EC. Cortical reorganization following bimanual training and somatosensory stimulation in cervical spinal cord injury: a case report. Phys Ther., 2007; 87:208-223.

20. McDonnell MN, Ridding MC. Afferent stimulation facilitates performance on a novel motor task. Exp Brain Res., 2006; 170:109-115.

21. Petrofsky, J., Prowse, M., Bain, M., Ebilane, E., Suh, H.J., Batt, J., Lawson, D., Hernandez, V., Abdo, A., Yang, T., Mendoz, E., Collins, K., Laymon, M. Estimation of the distribution of intramuscular current during electrical stimulation of the quadriceps muscle. Eur J Appl Physiol., 2008; 103:265-273 DOI 10.1007/ s00421-008-0700-3.

22. Thrasher A, Graham GM, Popovic MR. Reducing muscle fatigue due to functional electrical stimulation using random modulation of stimulation parameters. Artif Organs., 2005; 29(6):453-458.

23. Kleim JA. Neural plasticity and neurorehabilitation: teaching the new brain old tricks. J Commun Disord., 2011; 44:521-528.

24. Petrofsky JS, Lawson D, Suh HJ, Batt J. Effects of a 2, 3, and 4 electrode stimulator design on current dispersion on the surface and into the limb during electrical stimulation in controls and patients with wounds. J Med Eng Technol., 2007.

25. Zhu F, Leonard EF, Levin NW. Body composition modeling in the calf using an equivalent circuit model of multi-frequency bioimpedance analysis. Physiol Meas., 2005; 26(2):S133-S143.

26. Hewett P. Electric current, chap 23. In: Conceptual physics. Addison Wesely, 2006. St Petersburg.

27. Gobbo, M., Gaffurini, P., Bissolotti. L., Esposito, F., Orizio, C. Transcutaneous neuromuscular electrical stimulation: influence of electrode positioning and stimulus amplitude settings on muscle response. Eur J Appl Physiol., 2011; 111:2451-2459 DOI 10.1007/s00421-011-2047-4.

28. Lions GM, Leane GE, Clarke-Moloney M, O'Brien JV, Grace PA. An investigation of the eVect of electrode size and electrode location on comfort during stimulation of the gastrocnemius muscle. Med Eng Phys., 2004; 26:873-878.

29. Kitago T, Mazzocchio R, Liuzzi G, Cohen LG. Modulation of H-reflex excitability by tetanic stimulation. Clin Neurophysiol., 2004; 115:858-861.

30. Robinson A, Snyder-Mackler L. Clinical Electrophysiology: Electrotherapy and Electrophysiologic Testing. 3rd ed. Baltimore, MD 2008: Lippincott Williams \& Wilkins.
31. Lochynski D, Celichowski J, Korman P, Raglewska P. Changes of motor unit contractile output during repeated activity. Acta Neurobiol Exp., 2007; 67:23-33.

32. Barsi GI, Popovic DB, Tarkka IM, Sinkjaer T, Grey MJ. Cortical excitability changes following grasping exercise augmented with electrical stimulation. Exp Brain Res, 2008; 191:57-66.

33. Hamaoka T, McCully KK, Quaresima V, Yamamoto K, Chance B. Near-infrared spectroscopy/imaging for monitoring muscle oxygenation and oxidative metabolism in healthy and diseased humans. J Biomed Opt., 2007; 12(6):62-105.

34. Cettolo V, Ferrari M, Biasini V, Quaresima V. Vastus lateralis O2 desaturation in response to fast and short maximal contraction. Med Sci Sports Exerc, 2007; 39:1949-1959.

35. De Kroon JR, Ijzerman MJ, Lankhorst GJ, Zilvold G. Electrical stimulation of the upper limb in stroke. Stimulation of the extensors of the hand vs. alternate stimulation of flexors and extensors. Am J Phys Med Rehabil, 2004; 83: 592-600.

36. Kimberley TJ, Lewis SM, Auerbach EJ. Electrical stimulation driving functional improvements and cortical changes in subjects with stroke. Exp Brain Res. 2004; $154: 450-460$.

37. Johnson M, Martinson M. Efficacy of electrical nerve stimulation for chronic musculoskeletal pain: a metaanalysis of randomized controlled trials. Pain, 2007; 130:157-165.

38. Sheffler LR, Chae J. Neuromuscular electrical stimulation in neurorehabilitation. Muscle Nerve, 2007; 35:562-590.

39. Dehail P, Duclos C, Barat M. Electrical stimulation and muscle strengthening. Ann Readapt Med Phys, 2008; 51(6):441-451.

40. Stevens JE, Mizner RL, Snyder-Mackler L. Neuromuscular electrical stimulation for quadriceps muscle strengthening after bilateral total knee arthroplasty: a case series. J Orthop Sports Phys Ther, 2004; 34(1):21-29.

41. Petrofsky J. The effect of the subcutaneous fat on the transfer of current through skin and into muscle. Med Eng Phys., 2008;30:1168-76 22.

42. Alon G, Smith GV. Tolerance and conditioning to neuro-muscular electrical stimulation within and between sessions and gender. J Sport Sci Med, 2005; 4:395-405.

43. Vanderthommen M, Duchateau J. Electrical stimulation as a modality to improve performance of the neuromuscular system. Exerc Sport Sci Rev-2007; 35:180-5.

44. Petrofsky J, Laymon M, Prowse M. The transfer of current through skin and muscle during electrical stimulation with sine, square, Russian and interferential waveforms. J Med Eng Technol. 2009;33: 170-81.

45. Sujith OK. Functional electrical stimulation in neurological disorders. Eur J Neurol., 2008; 15: 437-444.

46. Maffiuletti NA, Herrero AJ, Jubeau M. Differences in electrical stimulation thresholds between men and women. Ann Neurol. 2008;63:507-12. 